\title{
Postpartum Hemorrhage and Maternal Deaths in North East India
}

\author{
K. Pratima Devi*, L. Ranjit Singh, L. Bimolchandra Singh, M. Rameshwar Singh, \\ N. Nabakishore Singh \\ Regional Institute of Medical Sciences, Imphal, India \\ Email: *pratimadutta09@gmail.com
}

Received 22 July 2015; accepted 18 September 2015; published 21 September 2015

Copyright (C) 2015 by authors and Scientific Research Publishing Inc.

This work is licensed under the Creative Commons Attribution International License (CC BY). http://creativecommons.org/licenses/by/4.0/

c) (i) Open Access

\begin{abstract}
Hemorrhage, usually occur in the postpartum period, is responsible between one quarter and one third of obstetric deaths. According to the world health organization, obstetrics hemorrhage causes 127,000 deaths annually worldwide and is the leading cause of maternal mortality. Postpartum hemorrhage (PPH) is a frequent complication of delivery and its incidence is commonly reported as $2 \%-4 \%$ after vaginal delivery and $6 \%$ after cesarean section with uterine atony being the cause in about $50 \%$ cases. The risk of dying from PPH depends not only on the amount and the rate of blood loss but also the health status of the woman. PPH remains the number one killer of mothers and accounts about $28 \%$ of all maternal deaths in developing countries. There is an increase risk in the PPH even in developed countries due to number of changes in recent years. In India, Maternal mortality rate (MMR) is $\mathbf{2 1 2}$ but in the state of Manipur (Regional Institute of Medical Sciences, RIMS), situated in the far corner of North East MMR is 91.68 (94 maternal deaths/102525 live births during year 2000-2010). Out of 94 deaths, $53.19 \%$ died due to hemorrhage and PPH accounts about $21.27 \%$ of total deaths. Again, almost all these PPH died within the first 24 hours of admission. High parity and home delivery brought late due to varied reasons with preexisting anemia are the common problems on analysis of maternal deaths due to PPH in our set up. Whatever the cause, death should be preventable and outcome is largely dependent upon timely interference and efficiency and vigor of medical practitioners. A pregnant woman and her family must understand the risks involved in each pregnancy. Even with different interventions and blood transfusion facility, maternal deaths cannot be brought down to zero. But the best available health care facilities should be made available to all.
\end{abstract}

\section{Keywords}

Postpartum Hemorrhage, Maternal Mortality, Cesarean

\footnotetext{
*Corresponding author.
}

How to cite this paper: Devi, K.P., Singh, L.R., Singh, L.B., Singh, M.R. and Singh, N.N. (2015) Postpartum Hemorrhage and Maternal Deaths in North East India. Open Journal of Obstetrics and Gynecology, 5, 635-638. 


\section{Introduction}

Worldwide about half a million women die as results of complications of pregnancy and childbirth [1]. Nearly all (99\%) of these deaths are in low and middle income countries [2]. Hemorrhage, usually occuring in the postpartum period, is responsible for between one quarter and one third of obstetric deaths [3]. According to the world health organization, obstetrics hemorrhage causes 127,000 deaths annually worldwide and is the leading cause of maternal mortality [4]. Primary postpartum hemorrhage is the loss of more than $500 \mathrm{ml}$ of blood within the first twenty-four hours of delivery or loss of any amount that is enough to cause hemodynamic instability in the mother or loss of more than $10 \%$ of the total blood volume. It is the most common form of postpartum hemorrhage [4] [5]. Secondary postpartum hemorrhage, on the other hand is defined as bleeding in excess of normal lochia after twenty-four hours and up to six weeks postpartum. In both the true loss is often underestimated due to the difficulty with the visual quantification [6]. The risk of dying from PPH depends not only on the amount and the rate of blood loss but also the health status of the woman. A major reason why many patients die from hemorrhage is because once bleeding starts, death can occur in around 2 hours compared to 10 hours for eclampsia and 72 hours for obstructed labor [7].

\section{Discussion}

Problem in India: India alone accounts for over 20 percent of the global maternal deaths even though it has only 16 percent of world population. The United Nations issued 8 Millennium Development Goals (MDG); the fifth goal (MDG-5) stipulated a reduction of the maternal mortality rate by 75 percent by 2015 [8]. The level of MMR in India has declined from over 750 in the sixties to about 400 in the nineties [8] [9]. It has further declined from 254 in 2004-06 to 212 in 2007-2009 [10] bulletin.

Definition and incidence: PPH is a frequent complication of delivery and its incidence is commonly reported as $2 \%$ - $4 \%$ after vaginal delivery and $6 \%$ after cesarean section with uterine atony being the cause in about $50 \%$ cases [11]. PPH remains the number one killer of mothers and accounts $28 \%$ of all maternal deaths in developing countries while in high income countries it accounts about $13 \%$ of maternal deaths [5]. There is an increase risk in the PPH due to number of changes in recent years in obstetric practice and maternal demographics; these include increase in the rate of cesarean delivery, a larger proportion of multiple gestation births, and more pregnant women of advanced maternal age [12] [13]. PPH caused by uterine atony resulting in transfusion often occurs in the absence of recognized risk factors [13]. A delay in the correction of hypervolemia and delay in the control of bleeding are the main avoidable factors in most maternal deaths caused by hemorrhage. Whatever the cause, death should be preventable and outcome is largely dependent upon timely interference, efficiency and vigor of medical practitioners.

Different Interventions: Active management reduces uterine atony and PPH. If it occurs the first priority is correction of hypovolumia with crystalloid and red cells. Uterotonic drugs, such as oxytocin or ergometrine, are used as prophylaxis. The early administration of prophylactic oxytocin is preferred and did not increase risks of manual removal of placenta and there is equal effectiveness in preventing PPH [14]. Nowadays, prostaglandin are administered orally, rectally, vaginally and parenterally with each having advantages and disadvantages in terms of availability, cost , stability, ease of administration and efficiency. Misoprostol does not require storage problem, cheap and stable with room temperature. Bimanual compression, uterine packing, Balloon Tamponade, and surgical interventions as B-Lynch suture, ligation of uterine artery, ovarian artery, internal iliac artery, embolization, and hysterectomy are different means of controlling hemorrhage. Blood transfusion also plays an important role.

Why mothers die? PPH contributes a big part in maternal deaths. Every minute a woman dies during labor or delivery. Maternal deaths are due to delays 1) delay in deciding to seek care because of self, family or the community to recognize the complication; 2) Delay in reaching the hospital due to poor transport, road conditions or far remote places; and 3) delay at the health care facility due to poor services, poor health infrastructure, incorrect treatment and too much work load. Though countries such as Bolivia, Brazil, China, Egypt, Morocco and Peru have made good progress toward achieving MDG-5 [16], India is still facing problem to reach the goal (Table 1).

Manipur at a glance: According to the latest bulletin of India published in 2011, the MMR is 212 but in the state of Manipur (Regional Institute of Medical Sciences, RIMS), situated in the far corner of North east MMR is 91.68 (94 maternal deaths/102525 live births) as in Table 2. Out of 94 deaths, 53.19\% died due to hemorrhage 
Table 1. Maternal Mortality Ratio (MMR) (2007-09) [10].

\begin{tabular}{cccc}
\hline State & MMR & State & MMR \\
\hline Assam & 390 & Bihar & 261 \\
Tamil Nadu & 97 & Kerala & 81 \\
West Bengal & 145 & India (total) & $\mathbf{2 1 2}$ \\
\hline
\end{tabular}

Table 2. PPH \& Maternal deaths in Manipur, India (2000-2010, RIMS, a tertiary institute).

\begin{tabular}{ccc}
\hline Causes & Maternal deaths (94/102, 525 live births) & Percentage \% \\
\hline PPH: Atony & 15 & 15.98 \\
Following Cesarean & 2 & 2.12 \\
Adherent placenta & 3 & 3.19 \\
Hemorrhage & 50 & 53.19 \\
\hline
\end{tabular}

and PPH accounts about $21.27 \%$ of total deaths. Almost all PPH died within the first 24 hours of admission. High parity and home delivery brought late due to varied reasons with preexisting anemia are the common problems on analysis [15].

Maternal deaths are still high in comparison with developed countries. Most women were from far-off places resulting in delayed intervention, and many were in poor general condition at the time of admission. The availability of blood banks at all first referral units (FRUs) and their proper functioning are needed. In our institute, blood bank is available round the clock but many are brought at the state of irreversible shock. PPH persists despite adequate antenatal care as atony cannot be always predicted and even with routine active management of third stage of labor. Sustained reductions will only be possible if modern high-quality obstetric care is made available to all women through a system of professional midwifery and referral hospital care in the context of political commitment and accountability of health providers [16]. Hemorrhage is still the leading cause of death in many studies of India published from Manipur, Delhi (22.7\%) and Orissa (28.57\%) etc. [17] [18]. PPH is again a major cause of hemorrhage and so early PPH need to be reduced by strengthening peripheral delivery facilities, active third stage management and early referral.

\section{Strategies to Reduce Deaths}

Individual level \& Family level: Every girl should be given special care to correct anemia and proper education. Pregnancy is to be planned after 18 years of age in good mental health and male partner should be always involved. The small family norm should be practiced with good effective contraceptives to avoid unsafe abortion. Health service level: Universal access to antenatal care, intranatal and postnatal care and $100 \%$ institutional delivery. Emergency obstetric care (EmOC), blood products and emergency medicines are to be made available to all round the clock. Community level: Social and bad cultural norms should be changed and health programs are to be arranged. Government level: Maternal laws on women health are to be reformed and good transport facilities on rural areas for good communication are to be easily available.

\section{Conclusion}

Mothers can be saved to a great extent but not 100\%. Developing countries have high number of maternal deaths as compared to developed countries. But it still cannot be brought down to zero even with very advanced facilities. We must try our level best with the best available intervention to save a pregnant woman. A pregnant woman and her family should take care and must understand the risks involved in each pregnancy. Level of obstetric care reflects the quality of care in the state.

\section{References}

[1] World Health Organization (2005) Attending to 136 Million Births, Every Year. Make Every Mother and Child Count. 
The World Report 2005. World Health Organization, Geneva, 62-63.

[2] World Health organization, U.N.C.F, United Nations Population Fund and World Bank (2007) Maternal Mortality in 2005. Estimates Developed by WHO, UNICEF, UNFPA, and the World Bank, Geneva. http://www.who.int/reproductive-health/publications/maternal_mortality_2005/mme_2005.pdf

[3] AbouZahr, C. (1998) Antepartum and Postpartum Hemorrhage. In: Murray, L.J. and Boston, A., Eds., Health Dimensions of Sex and Reproduction, Harvard School of Public Health on Behalf of the World Health Organization and the World Bank, 165-187

[4] World Health Organization (2008) Reducing the Burden: Postpartum Hemorrhage. http://www.who.int/maternal_child_adolescent/documents/newsletter/mps_newsletter_issue4.pdf

[5] Khan, K.S., et al. (2006) WHO Analysis of Causes of Maternal Death: A Systematic Review. The Lancet, 367, 10661074. http://dx.doi.org/10.1016/S0140-6736(06)68397-9

[6] Magnann, E.F., Evans, S., Chauhan, S.P., Lanneau, G., Fisk, A.D. and Morrison, J.C. (2005) The Length of the Third Stage of Labor and the Risk of Postpartum Hemorrhage. Obstetrics and Gynecology, 105, 290-293.

[7] Rao, K.A. (2001) Presidential Address. The Journal of Obstetrics and Gynecology of India, 51, 25-28.

[8] United Nations (2015) UN Millennium Development Goals. http://www.un.org/millenniumgoals/

[9] Bhat, P.N., Navneetham, K. and Rajan, S.I. (1995) Maternal Mortality in India: Estimates from a Regression Model. Studies in Family Planning, 26, 217-232. http://dx.doi.org/10.2307/2137847

[10] Registrar General (2011) Special Bulletin on Maternal Mortality in India 2007-09. Sample Registration System. Government of India, New Delhi.

[11] Amy, J.J. (1998) Severe Postpartum Hemorrhage: A Rational Approach. The National Medical Journal of India, 11, 86-88.

[12] MacDorman, M.F., Menacker, F. and Declercq, E. (2008) Cesarean Birth in the United States: Epidemiology, Trends, and Outcomes. Clinics in Perinatology, 35, 293-307. http://dx.doi.org/10.1016/j.clp.2008.03.007

[13] Bateman, B.T., Berman, M.F., Riley, L.E. and Leffert, L.R. (2010) The Epidemiology of Postpartum Hemorrhage in a Large, Nationwide Sample of Deliveries. Anesthesia and Analgesia, 110, 1368-1373. http://dx.doi.org/10.1213/ANE.0b013e3181d74898

[14] Karen, L.M., Steven, W.H. and Sim, S.G. (2006) Preventing Postpartum Hemorrhage: Managing the Third Stage of Labor. American Family Physician, 73, 1025-1028.

[15] Nour, N.M. (2008) An Introduction to Maternal Mortality. Reviews in Obstetrics \& Gynecology, 1, 77-81.

[16] Devi, K.P., Singh, C.M. and Devi, S.R. (2012) Maternal Mortality and Its Causes in a Tertiary Centre. The Journal of Obstetrics and Gynecology of India, 62, 168-171. http://dx.doi.org/10.1007/s13224-012-0169-1

[17] Dutta, D.K. (2012) Insight Maternal Mortality, an Indian Facebook. Jaypee Brothers Medical Publishers Pvt. Ltd., New Delhi.

[18] Ramachandra Bhat, P.B., Navada, M.H., Rao, S.V. and Nagarathna, G. (2013) Evaluation of Obstetric Admissions to Intensive Care Unit of Tertiary Referral Center in Coastal India. Indian Journal of Critical Care Medicine, 17, 34-37. http://dx.doi.org/10.4103/0972-5229.112156 